\title{
The Impact of Emerging Tropical Diseases in Neurology: Challenges to Accurate Diagnosis
}

\section{Francisco Javier Carod-Artal*}

Neurology Faculty, Virgen de la Luz Hospital, Cuenca, Spain

In western countries, the progressive appearance of tropical diseases affecting the central nervous system (CNS) has been associated with increased human migration, global warning, and tourism to tropical regions. At the same time, population growth, urbanisation, and deficiencies in water and sanitation systems lead to a re-emergence in endemic countries. Changes in world ecology have also modified the distribution of vectors involved in the transmission of some parasitary diseases [1].

Several neglected tropical diseases can cause severe disability due to involvement of the CNS. In fact, clinical cases of neuro-schistosomiasis, neurocysticercosis, and chagasic stroke are increasingly detected in western countries [2]. Nevertheless, early diagnosis and treatment may be hampered by the absence of adequate training programs in Tropical Neurology.

American trypanosomiasis or Chagas disease is one of the most important emergent health problems. In Europe and the United States, an increase in the number of asymptomatic Trypanosoma cruzi-infected people has been observed in the last decade due to the emigration of thousands of infected individuals from endemic areas [3]. Around 2\% of Latin-American immigrants may be infected with T. cruzi in the United States [4]. Few patients are aware of being infected, and vertical, transfusional and transplantational routes have accounted for all cases of transmission in nonendemic regions. In Europe, blood transfusion and congenital cases have being reported $[5,6]$. The association between ischemic stroke and T. cruzi infection is well known [7]. Many Chagas disease patients do not know that they harbor the chronic chagasic infection. So, ischemic stroke may be the first manifestation of Chagas disease in both asymptomatic T. cruzi-infected patients and also in the chronic stage of the disease $[8,9]$.

Schistosomiasis, a public health problem in many underdeveloped countries, continues to radiate to new geographical areas due to elevated mobility of populations, and the increase of tourism in endemic areas [10]. More than 200 million people worldwide are affected by schistosomiasis. In Europe, several hundreds of travel-associated schistosomiasis cases have been reported. Acute schistosomiasis may be the third most common cause of febrile disease imported from African countries, after malaria and rickettsial infections [11,12].

Neuroschistosomiasis, the infection of the CNS by Schistosoma spp., is a severe complication and neurological symptoms occur as a consequence of the immune reaction around the eggs deposited in the CNS $[13,14]$. In endemic regions, at least the $5.6 \%$ of patients admitted with a non-traumatic myelopathy may have spinal schistosomiasis [15]. Schistosome myeloradiculopathy affects the conus medullaris and/or cauda equine, although transverse myelitis presenting as flaccid arreflexic paraplegia can also occur [11]. Cerebral schistosomiasis may present with encephalopathy, headache, focal neurological deficit and seizures [16].

Most emerging viruses are associated with CNS infection. Some viruses causing encephalitis, such as Japanese encephalitis virus, have increased their geographic area whereas other virus, such as Nipah and Hendra viruses, have spread from animal reservoirs [1]. In the last years, air and sea transportation has introduced insect vectors that may transmit arbovirus into new areas. Aedes albopictus has been found in North America and Europe, and recently a strain of Chikungunya virus adapted to A. albopictus is spread in Europe $[17,18]$. In Europe, cases of autochthonous dengue fever and Chikungunya fever in France has been reported [19].

Dengue fever is the second most common mosquito-borne disease affecting human beings after malaria, and every year occur more than 50 million cases of dengue fever resulting in 25,000 fatalities [20]. Neurological manifestations of dengue infection are increasingly recognized and include dengue encephalopathy, dengue encephalitis, immune-mediated syndromes (acute disseminated encephalomyelitis, myelitis, Guillain-Barré syndrome), dengue muscle dysfunction and cerebral hemorrhagic complications [21].

Human T lymphotropic virus-I (HTLV-I) virus can mimic chronic neurological disorders and has been included in the differential diagnosis of primary and progressive multiple sclerosis. Neurological syndromes associated to HTLV-I infection include tropical spastic paraparesis or HTLV-I associated myelopathy, optic neuritis, cerebellar syndrome, axonal neuropathy, cognitive dysfunction and involvement of multiple cranial nerves [22].

A register for tropical diseases affecting the CNS is needed in order to obtain epidemiologic data about their impact in the daily practice of Neurology in western countries. Clinical research and protocols for early diagnosis and treatment should be developed, and a call for research papers in Tropical Neurology is needed. Specific training programs in Tropical Neurology should be developed to cover these deficiencies.

\section{References}

1. Coker R, Hunter BM, Rudge JW, Liverani M, Hanvoravongchai P (2011) Emerging infectious diseases in Southeast Asia: regional challenges to control. Lancet 377: 599-609.

2. Hotez PJ, Molyneux DH, Fenwick A, Kumaresan J, Sachs ES, et al. (2007) Control of neglected tropical diseases. N Engl J Med 357: 1018-1027.

3. Carod-Artal FJ, Gascón J (2010) Chagas disease and stroke. Lancet Neurol 9: 533-542.

*Corresponding author: Francisco Javier Carod-Artal, Neurology Faculty, Virgen de la Luz Hospital, Cuenca, Spain, E-mail: fjcarod-artal@hotmail.com

Received April 09, 2012; Accepted April 09, 2012; Published April 13, 2012

Citation: Carod-Artal FJ (2012) The Impact of Emerging Tropical Diseases in Neurology: Challenges to Accurate Diagnosis. J Neurol Neurophysiol 3:e105 doi:10.4172/2155-9562.1000e105

Copyright: @ 2012 Carod-Artal FJ. This is an open-access article distributed under the terms of the Creative Commons Attribution License, which permits unrestricted use, distribution, and reproduction in any medium, provided the original author and source are credited. 
Citation: Carod-Artal FJ (2012) The Impact of Emerging Tropical Diseases in Neurology: Challenges to Accurate Diagnosis. J Neurol Neurophysiol 3:e105. doi:10.4172/2155-9562.1000e105

Page 2 of 2

4. Schmunis GA, Yadon ZE (2010) Chagas disease: a Latin-American health problem becoming a world health problem. Acta Trop 115: 14-21.

5. Piron M, Vergés M, Muñoz J, Casamitjana N, Sanz S, et al. (2008) Seroprevalence of Trypanosoma cruzi infection in at-risk blood donors in Catalonia (Spain). Transfusion 48: 1862-1868.

6. Muñoz J, Coll O, Juncosa T, Vergés M, del Pino M, et al. (2009) Prevalence and vertical transmission of Trypanosoma cruzi infection among pregnant Latin American women attending 2 maternity clinics in Barcelona, Spain. Clin Infect Dis 48: $1736-1740$

7. Carod-Artal FJ, Vargas AP, Horan TA, Nunes LG (2005) Chagasic cardiomyopathy is independently associated with ischemic stroke in Chagas disease. Stroke 36: 965-970.

8. Carod-Artal FJ, Ribeiro Lda S, Vargas AP (2007) Awareness of stroke risk in chagasic stroke patients. J Neurol Sci 263: 35-39.

9. Carod-Artal FJ, Vargas AP, Falcao T (2011) Stroke in asymptomatic Trypanosoma cruzi-infected patients. Cerebrovasc Dis 31: 24-28.

10. Gryseels B, Polman K, Clerinx J, Kestens L (2006) Human schistosomiasis. Lancet 368: 1106-1118.

11. Nicolls DJ, Weld LH, Schwartz E, Reed C, von Sonnenburg F, et al. (2008) Characteristics of schistosomiasis in travellers reported to the GeoSentil Surveillance Network 1997-2008. Am J Trop Med Hyg 79: 729-734.

12. Bottieau E, Clerinx J, de Vega MR, Van den Enden E, Colebunders R, et al (2006) Imported Katayama fever: clinical and biological features at presentation and during treatment. J Infect 52: 339-345.
13. Carod-Artal FJ (2010) Neuroschistosomiasis. Expert Rev Anti Infect Ther 8: 1307-1318.

14. Naus CW, Chipwete J, Visser LG, Zijlstra EE, van Lieshout L (2003) The contribution made by Schistosoma infection to nontraumatic disorders of the spinal cord in Malawi. Ann Trop Med Parasitol 97: 711-721.

15. Carod Artal FJ, Vargas AP, Horan TA, Marinho PB, Coelho-Costa PH (2004) Schistosoma mansoni myelopathy: clinical and pathologic findings. Neurology 63: 388-391.

16. Carod-Artal FJ (2009) Tropical causes of epilepsy. Rev Neurol 49: 475-482.

17. Tyler KL (2009) Emerging viral infections of the central nervous system: part 2 Arch Neurol 66: 1065-1074.

18. Pialoux G, Gaüzere BA, Jauréguiberry S, Strobel M (2007) Chikungunya, an epidemic arbovirosis. Lancet Infect Dis 7: 319-327.

19. Gould EA, Gallian P, de Lamballerie X, Charrel RN (2010) First cases of autochthonous dengue fever and chikungunya fever in France: from bad dream to reality! Clin Microbiol Infect 16: 1702-1704.

20. World Health Organization (WHO) (2009) Dengue Guidelines for diagnosis, treatment, prevention and control. Geneva, Switzerland, WHO.

21. Wichmann O, Gascon J, Schunk M, Puente S, Siikamaki H, et al. (2007) Severe dengue virus infection in travelers: risk factors and laboratory indicators. J Infect Dis 195: 1089-1096.

22. Carod-Artal FJ (2009) [Immunopathogenesis and treatment of the myelopathy associated to the HTLV-I virus]. Rev Neurol 48: 147-155. 